\title{
Control of composition and structure for molybdenum nitride films synthesized using ion beam assisted deposition
}

\author{
M. S. Mudholkar and L. T. Thompson ${ }^{\text {a) }}$ \\ Department of Chemical Engineering, University of Michigan, Ann Arbor, Michigan 48109-2136
}

(Received 20 June 1994; accepted for publication 24 January 1995)

\begin{abstract}
The purpose of the research described in this article was to synthesize molybdenum nitride films with well-defined structures and stoichiometries using ion beam assisted deposition (IBAD). Approximately $400 \mathrm{~nm}$ thick films were prepared by the evaporative deposition of molybdenum while simultaneously bombarding the growing film with low energy $(250-1000 \mathrm{eV})$ nitrogen ions. The effects of ion-to-atom arrival rate ratio, ion angle of incidence, and ion energy on the film composition and phase constituents were examined. The film nitrogen to molybdenum stoichiometry increased linearly with increasing arrival rate ratio irrespective of the ion energy and varied significantly with changes in the ion angle of incidence. The latter was interpreted based on sputtering and reflection effects. The phase constituents were functions of all of the deposition parameters investigated. We propose that a single parameter, the effective energy density per deposited atom, can account for the effects of ion energy, mass, and angle of incidence. The effective energy density is approximately the ion energy divided by the ion range. The range incorporates the effects of ion mass and angle of incidence, as well as the energy. For low energy ions the energy density per depositing atom is proportional to $E^{1 / 2}$, a dependence that it shares with other models that have been developed to account for phase formation during IBAD. The advantage of the energy density treatment is that it has a more obvious influence on the temperature in the growth zone, a factor controlling phase formation. (C) 1995 American Institute of Physics.
\end{abstract}

\section{INTRODUCTION}

There is growing interest in the use of high surface area early transition metal nitrides and carbides as catalysts. Molybdenum nitride, for example, has been reported to have properties for hydrodenitrogenation ${ }^{1-3}$ and hydrodesulfurization $^{4,5}$ reactions that are superior to those of currently available commercial hydrotreatment catalysts. The catalytic properties of nitrides and carbides are functions of their surface structures and compositions for a variety of reactions. ${ }^{2,6,7}$ This behavior is believed to be a manifestation of structure sensitivity. Optimization of the catalytic properties of Mo nitride and other early transition metal nitrides and carbides requires a detailed understanding of the relationship between structure, composition, and function. In the research described in this article, we discuss our use of ion beam assisted deposition to synthesize well-defined molybdenum nitride thin films.

Ion beam assisted deposition (IBAD) is a technique which allows independent control of the deposition parameters so that materials with well-defined compositions and structures can be synthesized. It typically involves the deposition of atoms with simultaneous bombardment by energetic ions. If the ion beam consists of a reactive species, IBAD also results in the formation of a chemical compound. Bombardment of the growing film with energetic ions has been reported to produce beneficial modifications in characteristics such as adhesion, grain size, morphology, and film composition. ${ }^{8}$ Smidt $^{9}$ reviewed the various IBAD techniques

\footnotetext{
a) Author to whom correspondence should be addressed; Electronic mail: ltt@engin.umich.edu
}

and their use in depositing a variety of materials including nitride thin films.

Our effort focused on the deposition of molybdenum nitride films with varying bulk and surface structures and compositions. We attempted to correlate the structural and compositional properties of the films with the deposition parameters. This includes a description of the effects of the ion energy and ion angle of incidence on the film composition and phase constituents.

\section{EXPERIMENT}

A series of molybdenum nitride thin films was synthesized using ion beam assisted deposition. The deposition system consisted of a stainless steel ultrahigh vacuum chamber equipped with two CTI-8 cryopumps. The IBAD system is schematically illustrated in Fig. 1 . The base pressure in the chamber prior to deposition was less than $9 \times 10^{-9}$ Torr. High-purity Mo metal (Alfa, $99.5 \%$ pure) was evaporated using a Thermionics $10 \mathrm{~kW}$ two-hearth electron beam evaporation system. Molybdenum ingots were shaped into circular slugs ( $2.22 \mathrm{~cm}$ diameter, $2.54 \mathrm{~cm}$ thick), cleaned with acetone and methanol, then baked at $120^{\circ} \mathrm{C}$ for $1 \mathrm{~h}$ prior to placement into the evaporator. The fresh charge was then soaked at $35 \%$ of the maximum power for $4 \mathrm{~h}$ to eliminate impurities dissolved in the charge. The evaporator power was increased gradually until a stable deposition rate was achieved. The deposition rate was measured using a UHV bakeable crystal thickness monitor, and was regulated using an XTC Inficon deposition controller. A $3 \mathrm{~cm}$ Kaufman-type ion gun (Ion Tech Inc.) produced the nitrogen ion beam. High purity nitrogen gas (Matheson, $99.9999 \%$ pure) was employed to gencratc the ion beam, and to backfill the cham- 

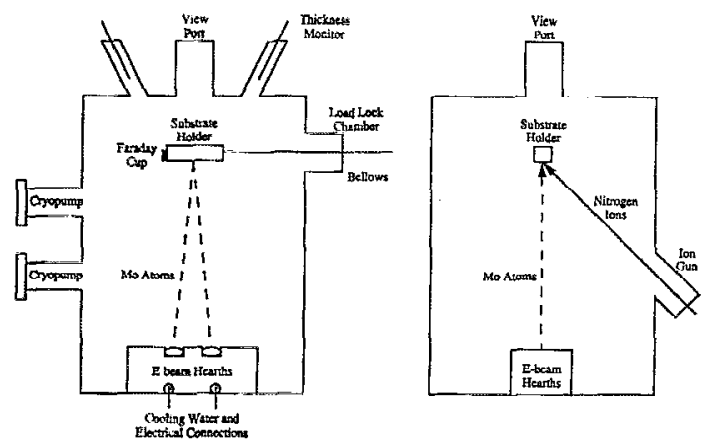

FIG. 1. Schematic of the ion beam assisted deposition system.

ber to a pressure of $2.2 \times 10^{-5}$ Torr during deposition. Ion beam energies of $250-1000 \mathrm{eV}$ were used, and the ion flux was monitored using a $3 \mathrm{~mm}$ diameter Faraday cup mounted on the substrate holder, approximately $5.5 \mathrm{~cm}$ away from the substrates. Nitrogen ion beam profiles were obtained prior to the depositions by translating the Faraday cup across the beam zone. The substrates were placed at the highest ion flux position. The measured ion current and atom deposition rate were continuously monitored via a computer interface to ensure stability of the deposition parameters. The evaporator and quartz thickness monitor were water cooled during deposition, and the substrates were cooled by circulating cool air through the copper substrate holder. The substrate holder was connected to a bellows system which allowed linear and rotational motion of the substrates. A bellows system was connected to the load lock chamber to allow easy mounting and dismounting of the substrates. Approximately $1 \mathrm{~cm}^{2} \mathrm{Si}(100)$ crystal and graphite substrates were used. The substrates were sputter cleaned by ion bombardment for $5 \mathrm{~min}$ prior to the deposition.

Two different ion beam angles, $10^{\circ}$ and $45^{\circ}$ to the substrate normal, were used. Molybdenum metal was deposited at a rate of $0.3 \mathrm{~nm} / \mathrm{s}$ and the nitrogen flux was varied to achieve different nitrogen to molybdenum arrival rate ratios. The composition of the nitrogen ion beam was taken as $89 \%$ $\mathrm{N}_{2}^{+}$and $11 \% \mathrm{~N}^{+}$, based on values reported by Van Vechten et al. ${ }^{10}$ Compositionally uniform films $\approx 400 \mathrm{~nm}$ thick were deposited. The films were passivated in approximately 1 Torr of $0.1 \% \mathrm{O}_{2}$ in $\mathrm{He}$ for $30 \mathrm{~min}$ prior to removal from the deposition system to prevent bulk oxidation.

The compositions of the films were determined by $\mathrm{Ru}$ therford backscattering spectrometry (RBS). A $2 \mathrm{MeV} \mathrm{He}^{++}$ beam at $165^{\circ}$ was used, and the spectra were analyzed using the RUMP ${ }^{11}$ analysis software. Phase constituents were determined using a Rigaku DMAX-B X-ray diffractometer, which employed a rotating $\mathrm{Cu}$ anode target producing $\mathrm{Cu} K_{\alpha}$ radiation.

\section{RESULTS AND DISCUSSION}

\section{A. Film composition}

The film composition was a strong function of the arrival rate ratio and ion angle of incidence. Figure 2 illustrates the film nitrogen to molybdenum stoichiometry as a function of the nitrogen to molybdenum arrival rate ratio for different

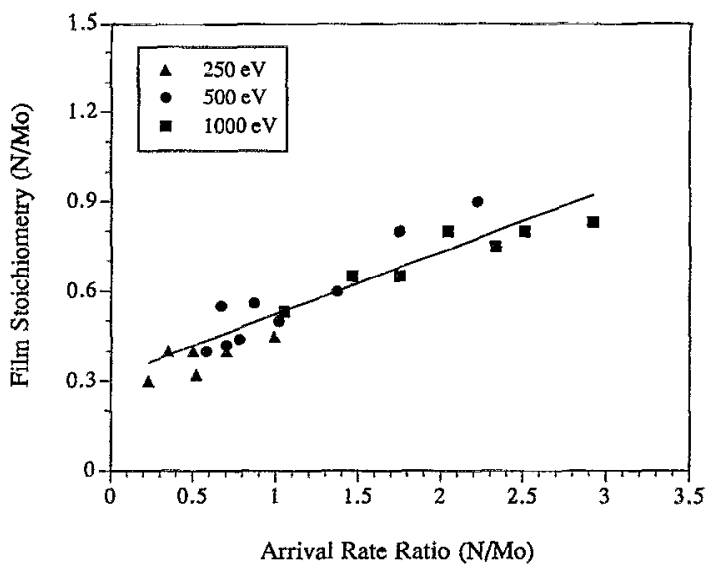

FIG. 2. Variation in film nitrogen to molybdenum stoichiometry with the arrival rate ratio for different energies using a $45^{\circ}$ ion angle of incidence.

ion energies at a $45^{\circ}$ ion angle of incidence. The N/Mo stoichiometry increased linearly with the arrival rate ratio and a single straight line adequately represented the data for different energies. This suggested that the film composition was independent of the ion energy employed. Within experimental error, the $y$-intercept was $\mathrm{N} / \mathrm{Mo} \approx 0.35$ for each energy. This value corresponds to the amount of nitrogen incorporated into the film due to nitrogen backfilled into the deposition chamber. Nitrogen incorporation from the ion beam was a function of the angle of incidence. The $10^{\circ}$ angle of incidence resulted in films with higher N/Mo ratios than those produced using a $45^{\circ}$ angle (Fig. 3). This behavior can be explained based on the reflection and sputtering of Mo and nitrogen from the growing film.

A material balance yields the rate of molybdenum incorporation into the growing film, $F_{\text {Mo }}^{i}$,

$$
F_{\mathrm{Mo}}^{i}-F_{\mathrm{Mo}}-S_{\mathrm{Mo}} F_{\mathrm{N}} \text {, }
$$

where $F_{\mathrm{Mo}}$ is the molybdenum deposition rate, $S_{\mathrm{Mo}}$ is the effective sputtering coefficient for $\mathrm{Mo}$, and $F_{\mathrm{N}}$ is the incident nitrogen flux..$^{12-14}$ The rate of molybdenum incorporation

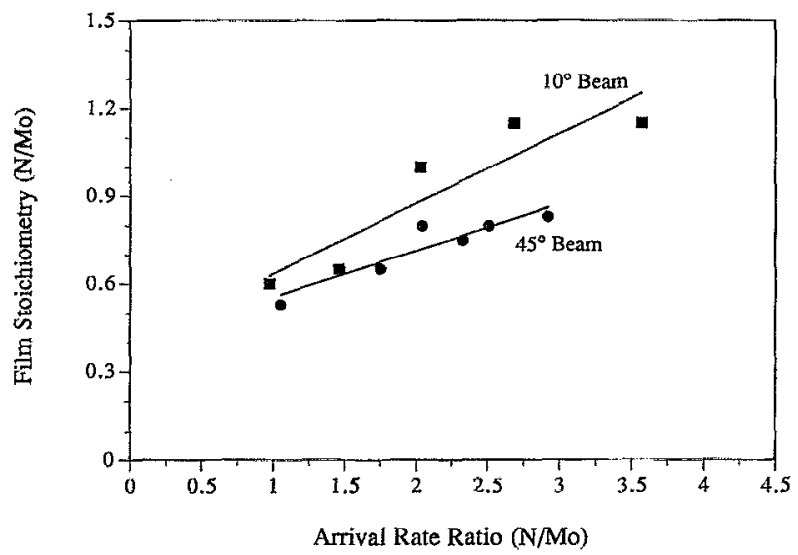

FIG. 3. Variation in film nitrogen to molybdenum stoichiometry with the arrival rate ratio for different ion angles of incidence using $1000 \mathrm{eV}$ ions. 


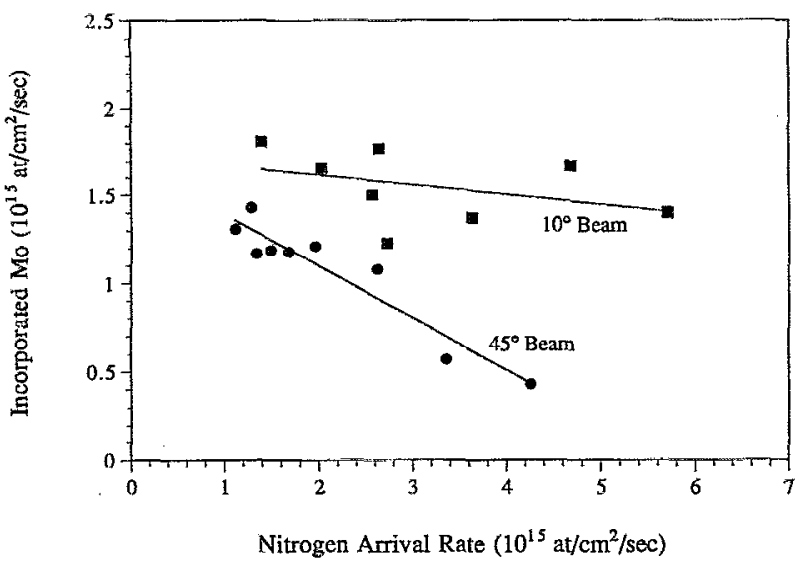

FIG. 4. Variation in molybdenum incorporation rate with the nitrogen arrival rate for different ion angles of incidence using $500 \mathrm{eV}$ ions.

into the film was calculated based on the film mass thickness, composition, and deposition time. Figure 4 shows the molybdenum incorporation rate as a function of the nitrogen ion arrival rate for $500 \mathrm{eV}$ ion beam assisted depositions at different ion incidence angles. A straight line, with a slope characteristic of the effective molybdenum sputtering coefficient, adequately fit the data. The sputtering coefficients for angles of $10^{\circ}$ and $45^{\circ}$ were 0.06 and 0.29 , respectively. For $500 \mathrm{eV}$ nitrogen ions, TRIM calculations predicted sputtering coefficients of 0.26 and 0.29 , for $10^{\circ}$ and $45^{\circ}$ angles of incidence, respectively. Note that the intercept based on linear regression analysis was $\approx 1.7 \times 10^{15}$ at. $/ \mathrm{cm}^{2} / \mathrm{s}$, which when multiplied by the atomic density of molybdenum approximates the measured Mo deposition rate.

The rate of nitrogen incorporation into the film, $F_{\mathrm{N}}^{i}$, as determined from a material balance is

$$
F_{N}^{i}=F_{\mathrm{N}}\left(1-r-S_{\mathrm{N}}\right)+F_{\text {gas }},
$$

where $F_{\mathrm{N}}$ is the nitrogen ion arrival rate, $r$ and $S_{\mathrm{N}}$ are the effective reflection and sputtering coefficients for nitrogen, respectively, and $F_{\text {gas }}$ is the rate of nitrogen incorporation due to $\mathrm{N}_{2}$ in the deposition chamber. The rate of nitrogen incorporation was determined from the film mass thickness and composition.

The nitrogen incorporation trends changed significantly when the ion beam angle of incidence was varied. The relationship between $F_{\mathrm{N}}^{i}$ and $F_{\mathrm{N}}$ is illustrated in Fig. 5. The lines correspond to least squares regression fits of the data. For a $45^{\circ}$ angle, the rate of nitrogen incorporation increased and then decreased slightly as the nitrogen arrival rate was increased. This indicated that the sum of the reflection and sputtering coefficients was a nonlinear function of the arrival rate ratio. The nonlinearity was probably a consequence of the dependence of reflection and sputtering on the incorporation of nitrogen. This dependence can be attributed to a number of factors. First, the sputtering coefficient is a function of the surface composition, and hence the incident nitrogen flux. Second, the near surface nitrogen composition increases with increasing nitrogen flux, resulting in higher nitrogen sputtering yields. The projected range of nitrogen

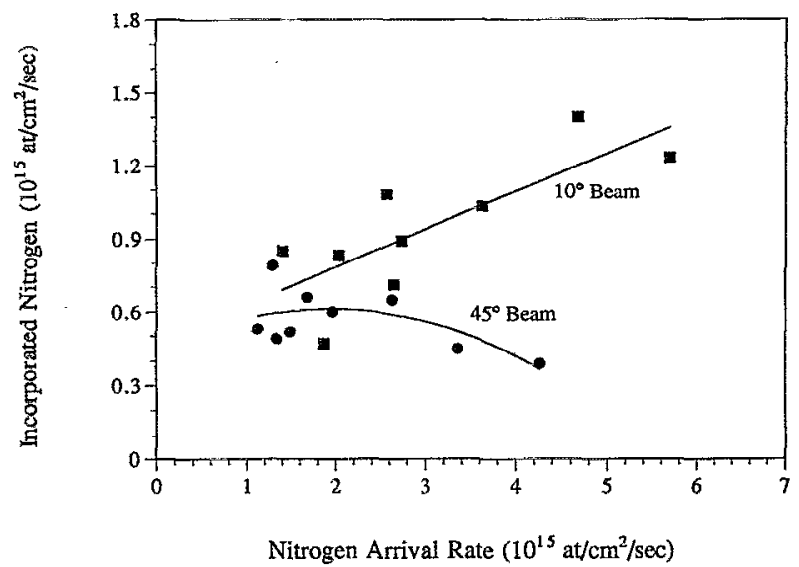

FIG. 5. Variation in nitrogen incorporation rate with the nitrogen arrival rate for different ion angles of incidence using $500 \mathrm{eV}$ ions.

decreases with increasing near surface nitrogen composition. In addition, as the surface nitrogen composition increases, the average surface atomic mass decreases and the reflection coefficient should decrease.

For the $10^{\circ}$ angle, the relationship between $F_{\mathrm{N}}^{i}$ and $F_{\mathrm{N}}$ was well represented by a straight line, indicating that the sum of the reflection and sputtering coefficients was constant. This was not expected since the sputtering and reflection coefficients are independent and nonlinear functions of the nitrogen arrival rate. The $y$-intercept, however, agrees with the intercepts for the arrival rate ratio and molybdenum incorporation relationships.

While the ion energy did not influence the film composition, it significantly affected the phase constituents. The effect of ion energy can be isolated by considering films of constant composition. Figure 6 shows the variation in phase constituents with the ion beam energy. At lower ion energies, $\beta-\mathrm{Mo}_{16} \mathrm{~N}_{7}$ was selectively formed. As the energy was increased, there was a gradual transition from $\beta-\mathrm{Mo}_{16} \mathrm{~N}_{7}$ to mixtures of $\beta-\mathrm{Mo}_{16} \mathrm{~N}_{7}$ and $\delta$-MoN, with $\beta-\mathrm{Mo}_{16} \mathrm{~N}_{7}$ being the prominent phase at lower film compositions, and $\delta$-MoN be-

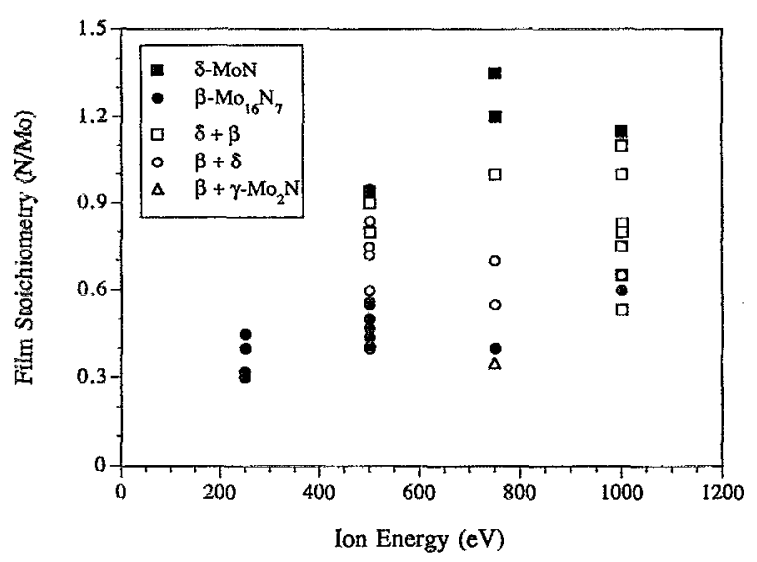

FIG. 6. Effect of ion energy on the phase constituents. 


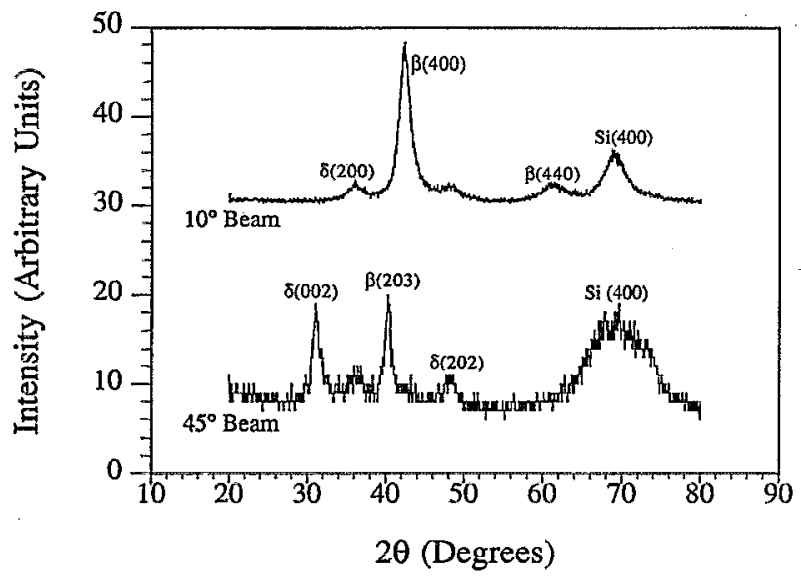

FIG. 7. Effect of ion angle of incidence on orientation of crystallites in the films.

coming the prominent phase at higher film compositions. At higher ion energies and $\mathrm{N} / \mathrm{Mo}$ ratios, single phase $\delta$-MoN was produced.

\section{B. Crystallite orientation}

Variations in the ion beam angle of incidence produced significant changes in the orientation of crystallites in the films. Figure 7 compares the diffraction patterns for films synthesized using the same beam energy $(500 \mathrm{eV})$ and arrival rate ratio $(\approx 2.3)$, but different ion incidence angles. Note that the N/Mo ratios for these films $(\approx 0.9)$ were within experimental error of each other. For the $45^{\circ}$ angle of incidence, a mixture of $\delta \mathrm{MoN}$ with the (002) planes and $\beta-\mathrm{Mo}_{16} \mathrm{~N}_{7}$ with the (203) planes preferentially oriented parallel to the substrate surface was produced. For the $10^{\circ}$ angle, the same conditions produced predominantly $\beta-\mathrm{Mo}_{16} \mathrm{~N}_{7}$ with the (400) planes oriented parallel to the substrate surface.

Preferential orientation effects have been attributed to ion channeling ${ }^{15-20}$ and/or to variations in the sputtering yield with orientation. ${ }^{21,22}$ Dobrev $^{20}$ suggested that channeling directions aligned to the ion beam would remain coolest during the resulting thermal spike, and would serve as nuclei for recrystallization. Bradley ${ }^{21,22}$ proposed that orientations with higher sputtering yields are removed faster therefore the film grows to favor the low sputtering yield orientations. Both explanations are consistent with our experimental observations, as the orientation depended on the ion energy and ion flux (controlling factors for the thermal spike and sputtering) and the ion angle of incidence (governs the channeling directions).

\section{Phase formation}

The ion energy had a significant cffect on the phase constituents. Phase formation is governed by the temperature, time at temperature, and composition of the reactant mixture. McKenzie ${ }^{23}$ suggested that during deposition, the film consists of an active growth zone near the film surface, which is supported on the previously deposited material and substrate.
TABLE I. TRIM simulation results for nitrogen ion bombardment onto mo lybdenum nitride film.

\begin{tabular}{cccccc}
\hline $\begin{array}{c}\text { Ion angle } \\
\text { of incidence }\end{array}$ & $\begin{array}{c}\text { Ion energy } \\
(\mathrm{eV})\end{array}$ & $\begin{array}{c}\text { Sputtering } \\
\text { coeff. } S_{\mathrm{Mo}}\end{array}$ & $\begin{array}{c}\text { Sputtering } \\
\text { coeff. } S_{\mathrm{N}}\end{array}$ & $\begin{array}{c}\text { Reflection } \\
\text { coeff. }(r)\end{array}$ & $\begin{array}{c}\text { Ion range } \\
(\mathrm{nm})\end{array}$ \\
\hline $45^{\circ}$ & 1000 & 0.654 & 0.307 & 0.294 & 2.3 \\
$45^{\circ}$ & 500 & 0.405 & 0.226 & 0.308 & 1.5 \\
$45^{\circ}$ & 250 & 0.290 & 0.212 & 0.324 & 1.1 \\
$45^{\circ}$ & 125 & 0.118 & 0.061 & 0.363 & 0.6 \\
$10^{\circ}$ & 1000 & 0.541 & 0.255 & 0.188 & 2.7 \\
$10^{\circ}$ & 500 & 0.420 & 0.186 & 0.202 & 1.7 \\
$10^{\circ}$ & 250 & 0.262 & 0.140 & 0.211 & 1.3 \\
$10^{\circ}$ & 125 & 0.139 & 0.048 & 0.251 & 0.7 \\
\hline \hline
\end{tabular}

It is difficult to measure the temperature in the growth zone during reactive ion bearn assisted deposition; however, there are considerations that play a role in defining the temperature. The energy deposited by the bombarding ions is expected to be the primary controlling factor.

Temperature in the growth zone will depend on the rates of energy input by the ions and atoms, the heat of reaction between the ions and atoms, the rate of energy loss to the chamber environment and substrate, and the volume of the growth zone. While the depth of the active growth zone was not determined experimentally, the ion range is believed to be a reasonable estimator of its thickness. For the low energies employed in this research, TRIM calculations indicated that the projected ion ranges were $<3 \mathrm{~nm}$. Since the depth of the growth zone is much smaller than the film thickness and the film surface represents a negligible heat flux boundary $\left(<0.01 \mathrm{~W} / \mathrm{cm}^{2}\right)$, the temperature in the growth zone should be nearly uniform.

The energy flux to the growing film is simply the product of the ion energy, $E$, and the ion flux, $J$. The energy per depositing atom would therefore be

$$
\frac{\text { Energy }}{\text { Atom }}=\frac{J}{a} \times E,
$$

where $a$ is the atom deposition rate. Considering that the ion energy dissipates in a depth that is approximately equal to the ion range, $\lambda$, an effective energy density per deposited atom, $E_{s}$, can be defined as

$$
E_{s}=\frac{J}{a}\left\{\frac{E}{\lambda}\right\} \text {. }
$$

Note that the projected range is influenced by the ion energy, mass, and angle of incidence. Heavier ions have shorter ranges, and hence the energy density per deposited atom would increase with increasing ion mass. For an ion beam consisting of multiple species, this expression becomes

$$
E_{s}=\sum_{i} \frac{J_{i}}{a}\left\{\frac{E_{i}}{\lambda_{i}}\right\},
$$

where the subscript represents the particular ionic species.

Figure 8 shows the phase constituents in the film as a function of the effective energy density per deposited atom and the composition. The ion ranges determined based on TRIM simulations are summarized in Table I. At low N/Mo 


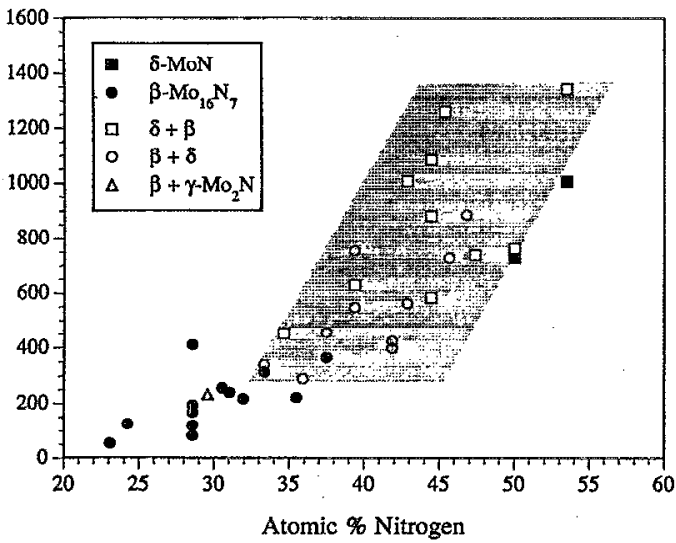

FIG. 8. Diagram summarizing the influence of film composition and effective energy density per deposited atom on the phase constituents. Shaded part indicates the two-phase region.

ratios and $E_{s}$ values, only $\beta-\mathrm{Mo}_{16} \mathrm{~N}_{7}$ was formed. As the N/Mo ratio and/or $E_{s}$ were increased, mixtures of $\beta-\mathrm{Mo}_{16} \mathrm{~N}_{7}$ and $\delta$-MoN formed. At $\mathrm{N} / \mathrm{Mo} \approx 1$ and high $E_{s}$, only $\delta \mathrm{MoN}$ was produced. The two-phase region is shaded.

While the ion energy has been implicated as a factor controlling thin film phase formation, orientation, and density, ${ }^{24-27}$ several recent reports suggest that phase formation, stress annealing behavior, and changes in optical properties during IBAD are controlled by the ion momentum transferred to the growing film per deposited atom. ${ }^{28-34}$ For example, Messier and co-workers ${ }^{28}$ reported that the formation of cubic boron nitride was observed unly after a critical momentum-per-atom threshold was exceeded. The functional relationship for the ion momentum per atom, $P / a$, is

$$
\frac{P}{a}=\sum_{i} \frac{J_{i}}{a} \sqrt{2 m_{i} \gamma_{i} E_{i}}, \quad \gamma_{i}=\frac{4 m_{i} M}{\left(m_{i}+M\right)^{2}}
$$

where $m_{i}$ is the mass of the ionic species $i, M$ is the mass of the atomic species; and $\gamma_{i}$ is the maximum energy transfer from ion $i$ to the deposited atoms. For a constant composition ion beam, this expression reduces to

$$
\frac{P}{a}=K_{1}\left\{\frac{J}{a}\right\} E^{1 / 2},
$$

where $K_{1}$ is a function of the beam composition. A similar expression can be derived based on the effective energy density when we consider the relationship between projected range and energy. For the low energies typical of IBAD, the range is proportional to $E^{1 / 2},{ }^{35-37}$ therefore, the effective energy density per deposited atom would be

$$
E_{s}=K_{2}\left\{\frac{J}{a}\right\} E^{1 / 2}
$$

where $K_{2}$ is a function of beam composition. The benefit of the effective energy density treatment over the momentum per-atom is that the energy deposition rate has a more obvious effect on the temperature of the film, a determinant in phase formation.

\section{CONCLUSIONS}

A series of molybdenum nitride films was synthesized using ion beam assisted deposition. The ion energy (250$1000 \mathrm{eV})$, nitrogen to molybdenum arrival rate ratio $(0.23$ $0.57)$, and ion angle of incidence $\left(10^{\circ}\right.$ and $\left.45^{\circ}\right)$ were varied in an attempt to regulate the film composition and phase constituents. We found that the nitrogen to molybdenum ratio in the films varied linearly with the arrival rate ratio. Data for different ion energies were well represented by a single line suggesting that the stoichiometry was not a function of the ion energy within the range of energies studied. The mechanism of nitrogen incorporation did, however, change with the ion angle of incidence. For a $10^{\circ}$ angle of incidence, the amount of nitrogen incorporated into the film increased linearly with the nitrogen arrival rate. For a $45^{\circ}$ angle of incidence, nitrogen incorporation increased then decreased with increasing nitrogen arrival rate. The results were interpreted in terms of sputtering and reflection effects. The measured molybdenum sputtering coefficients were 0.06 and 0.29 for the $10^{\circ}$ and $45^{\circ}$ angles, respectively, compared to values of 0.26 and 0.29 from TRIM predictions. The ion angle of incidence also had a significant effect on the orientation of crystallites in the films. This texturing is believed to be a consequence of ion channeling effects.

The phases present in the films were functions of the arrival rate ratio, ion energy, and ion angle of incidence. For a given film composition, we propose that the effective energy density per deposited atom was the factor controlling phase formation. This parameter accounts collectively for most of the deposition parameters and should be a determinant for the temperature in the active growth zone. The functional form for the efrective energy density per deposited atom matches that for the momentum-per-atom at low energies where the range is proportional to $E^{1 / 2}$.

\section{ACKNOWLEDGMENTS}

Use of facilities in the Michigan Ion Beam Laboratory is acknowledged. The authors would also like to acknowledge Dr. Graham Hubler of the Naval Research Laboratory for helpful discussions. This work was supported by the National Science Foundation (CTS-898701).

${ }^{1}$ J. C. Schlatter, S. T. Oyama, J. E. Metcalfe, and J. M. Lambert, Ind. Eng. Chem. Res. 27, 1648 (1988).

${ }^{2}$ J.-G. Choi, J. R. Brenner, C. W. Colling, B. G. Demczyk, J. L. Dunning, and L. T. Thompson, Catal. Today 15, 201 (1992).

${ }^{3}$ C. W. Colling and L. T. Thompson, J. Catal. 146, 193 (1994).

${ }^{4}$ D. J. Sajkowski and S. T. Oyama, in Symposium on the Chemistry of W/Mo Catalysis, 199th ACS National Meeting, Boston, Massachusetts, April 22-27, 1990, Prep. Am. Chem. Soc. Div. Pet. Chem. (1990).

${ }^{5}$ E. J. Markel and J. W. Van Zee, J. Catal. 126, 6643 (1990).

${ }^{6}$ B. G. Demczyk, J.-G. Choi, and L. T. Thompson, Appl. Surf. Sci. 78, 63 (1994).

${ }^{7}$ J.-G. Choi, J. R. Brenner, and L. T. Thompson, J. Catal. 153, (1995).

${ }^{8}$ J. K. Hirvonen, Mater. Sci. Rep. 6. 215 (1991).

${ }^{9}$ F. A. Smidt, Inter. Mater. Rev. 35, 61 (1990).

${ }^{10}$ D. Van Vechten, G. K. Hubler, and E. P. Donovan, Vacuum 36, 841 (1986).

${ }^{11}$ L. R. Doolittle, Nucl. Instrum. Methods Phys. Res. B 9, 344 (1983).

${ }^{12}$ D. Van Vechten, G. K. Hubler, E. P. Donovan, and F. D. Correll, J. Vac. Sci. Technol. A 8, 821 (1990). 
${ }^{13}$ G. K. Hubler, D. Van Vechten, E. P. Donovan, and C. A. Carosella, J. Vac. Sci. Technol. A 8, 831 (1990).

${ }^{14}$ E. P. Donovan, G. K. Hubler, M. S. Mudholkar, and L. T. Thompson, Surf. Coat. Technol. 66, 499 (1994).

${ }^{15}$ P. Wang, D. A. Thompson, and W. W. Smeltzer, Nucl. Instrum. Methods Phys. Res. B 7/8, 97 (1985).

${ }^{16}$ K. Kobayashi, S. Namba, T. Fujihana, Y. Dai, and M. Iwaki, Nucl. Instrum. Methods Phys. Res. B 33, 689 (1988).

${ }^{17}$ Y. Andoh, K. Ogata, H. Yamaki, and S. Sakai, Nucl. Instrum. Methods Phys. Res. B 39, 158 (1989).

${ }^{18}$ G. N. Van Wyk and H. J. Smith, Nucl. Instrum. Methods 170, 433 (1980).

${ }^{19}$ K. S. Grabowski, R. A. Kant, and S. B. Quadri, Mater. Res. Soc. Symp. Proc. 128, 279 (1989).

${ }^{20}$ D. Dobrev, Thin Solid Films 92, 41 (1982).

${ }^{21}$ R. M. Bradley, J. M. E. Harper, and D. A. Smith, J. Appl. Phys. 60, 4160 (1986).

${ }^{22}$ R. M. Bradley, J. M. E. Harper, and D. A. Smith, J. Vac. Sci. Technol. A 5, 1792 (1987).

${ }^{23}$ D. R. McKenzie, J. Vac. Sci. Technol. B 11, 1928 (1993).
${ }^{24}$ N. Savvides, Thin Solid Films 163, 13 (1988).

${ }^{25}$ Y. Cong, R. W. Collins, R. Messier, K. Vedam, G. F. Epps, and H. Windischmann, J. Vac. Sci. Technol. A 9, 1123 (1991).

${ }^{26}$ P. Ziemann and E. Kay, J. Vac. Sci. Technol. A 1, 512 (1983).

${ }^{27}$ E. Kay, F. Parmigiani, and W. Parrish, J. Vac. Sci. Technol. A 5, 44 (1987).

${ }^{28}$ D. J. Kester and R. Messier, J. Appl. Phys. 72, 504 (1992).

${ }^{29}$ J. D. Targove and H. A. Macleod, Appl. Opt. 27, 3779 (1988).

${ }^{30}$ H. Windischmann, J. Appl. Phys. 62, 1800 (1987).

${ }^{31} \mathrm{H}$. Windischmann, J. Vac. Sci. Technol. A 9, 2431 (1991).

${ }^{32}$ C. K. Hwangbo, L. J. Lingg, J. P. Lehan, H. A. Macleod, J. L. Makous, and S. Y. KKim, Appl. Opt. 28, 2769 (1989).

${ }^{33}$ S. M. Rossnagel and J. J. Cuomo, Thin Solid Films 171, 143 (1989).

${ }^{34}$ D. W. Hoffman and M. R. Gaerttner, J. Vac. Sci. Technol. 17, 425 (1980).

${ }^{35}$ D. J. Skyrme, Nucl. Instrum. Methods 57, 61 (1967).

${ }^{36}$ M. A. Kumakhov and F. F. Komarov, Energy Loss and Ion Ranges in solids (Gordon and Breach, New York, 1981), pp. 262-266.

${ }^{37}$ D. R. Brighton and G. K. Hubler, Nucl. Instrum. Methods Phys. Res. B 28, 527 (1987). 